\title{
Study on the Efficiency Improvement of Hunan's Common Logistics of Agricultural Products Against the Background of Rural Revitalization*
}

\author{
Shijun Yuan \\ Hunan Modern Logistics College \\ Changsha, China
}

\author{
Jianhua Chen** \\ Hunan Modern Logistics College \\ Changsha, China \\ ***Corresponding Author
}

\begin{abstract}
The rural revitalization strategy and common logistics are both the current focus of attention and research object, such as what is the demand of rural revitalization on the development of logistics industry, how does the logistics industry support the realization of rural revitalization strategy, etc. This paper firstly reviews the current research literature on the efficiency of agricultural products logistics, then defines the indexes of efficiency of agricultural products logistics, analyzes influence factors of efficiency of agricultural products logistics, and constructs a common logistics system for agricultural products, so as to advance the development of agricultural products logistics.
\end{abstract}

Keywords-agricultural products; common logistics; efficiency

\section{INTRODUCTION}

China's major agricultural products will keep on growth in their production and demand for a long time in the future, which will create opportunities for the development of agricultural products logistics. Meanwhile, personalized demand and high-end quality of agricultural products logistics service will also bring new challenges to the improvement of efficiency of agricultural products logistics. Common logistics and big data are important driving forces of agricultural products logistics innovation. Common logistics improves agricultural products logistics from the operation, organization and management of agricultural products. However, the big data platform can mine, summarize, classify, refine and integrate data resources from the warehousing, circulation, processing, loading and unloading, cargo packaging, distribution, and transportation and other links of the massive and scattered agricultural products logistics supply chain to discover new laws and value information. And, it can be used to effectively promote the implementation of common logistics, so as to further improve the efficiency of agricultural products logistics and

*Fund: 2018 Hunan philosophy and social science fund base project "Research on the Establishment of Rural Logistics System in Hunan Province Based on the Strategy of Rural Revitalization" (18JD43) and the phased research result of Hunan Social Science Achievement Review Committee "Research on the Countermeasure System of Rural Logistics Development Based on the Strategy of Rural Revitalization" (XSP19YBC277) create new value.

\section{LITERATURE REVIEW}

Yang Furong (2013) believed that strong logistics capability could effectively connect the production, circulation and consumption of agricultural products, which was conducive to improving the circulation efficiency of agricultural products. In the study of efficiency and evaluation of agricultural products logistics, Yang Jun, Wang Houjun and Yang Chun (2011) adopted the method of distance function and nonparametric linear programming, and Chen Ling (2014) used the modified DEA model, and Cui Zhenhong, Wang Jiaxu and Hua Zhen (2015) adopted the method of Malmquist index analysis based on DEA, and Wang Xuhui, and Wen Jingyi (2015) adopted the SFA analysis method based on provincial panel data. Fang Kai (2013) built a performance evaluation system consisting of six secondary indexes, including financial management, cold chain process, customer service, collaborative capacity, environmental protection and development ability, and 25 tertiary indexes, including return on total assets, etc. Zheng Zhi (2013) measured the efficiency indexes of agricultural products logistics, such as the loss rate of agricultural products logistics, speed of agricultural products logistics, ratio of agricultural products logistics cost to its sales, etc. Based on the traditional efficiency assessment indexes, $\mathrm{Li}$ Yaohua (2015) tried to include the relevant impact indexes of logistics industry on the ecological environment into the evaluation, and constructed an efficiency evaluation system for cold chain logistics enterprises from six aspects based on the perspective of green supply chain.

In the meantime, Li Chuang's research (2012) showed that the third-party logistics model was more conducive to enhancing the operation efficiency of agricultural products logistics than the traditional wholesale market model. Le Ting (2012) held that agricultural products logistics capability (logistics infrastructure capability, logistics coordination capability, logistics operation capability and policy environment support capability) had a significant positive impact on agricultural products circulation efficiency. According to Xu Liangpei and Li Shuhua (2013), the improvement and enhancement of China's agricultural 
cost of agricultural products includes their transportation cost, storage cost, distribution cost, handling cost, packaging cost, circulation and processing cost, logistics information service cost, etc. Implicit logistics cost of agricultural products includes cost of stock occupation, loss from stock falling price, out-of-stock costs, etc. information in the core process of logistics in the micro perspective. From the perspective of common logistics, Jiang Xuelin, Wang Shaofen and Huang Fuhua (2016) thought that the efficiency of agricultural products logistics could be improved from organization degree of logistics subject, logistics information system, income distribution mechanism, common logistics mode and logistics infrastructure.

As can be seen, despite the fact that many experts and scholars have conducted researches on the significance of agricultural products logistics, and influence factors, evaluation index and improvement strategy of agricultural products logistics efficiency, there is almost no literature on improving agricultural products logistics efficiency directly from the perspective of big data.

\section{ANALYSIS ON EVALUATION INDEXES AND INFLUENCE FACTORS OF AGRICULTURAL PRODUCTS LOGISTICS EFFICIENCY}

\section{A. Evaluation Indexes of Agricultural Products Logistics Efficiency}

The efficiency of agricultural products logistics is the ratio of the output of agricultural products logistics to the input of agricultural products logistics resources. The output of agricultural products logistics service can be quantified as the customer service level of agricultural products logistics. The input of agricultural products logistics represents its cost. Therefore, in other words, the efficiency of agricultural products logistics can be a comprehensive system of the cost input of agricultural products logistics and the level of logistics services it provides, which can be embodied in the two efficiency indexes of agricultural products logistics service quality and agricultural products logistics cost.

The service quality and efficiency indexes of agricultural products logistics include service quality indexes of agricultural products logistics providers (availability, timeliness and reliability) and perceived quality indexes of agricultural products logistics customers (potential quality, process quality and result quality). Among them, potential quality is an index to measure the hardware and software conditions of logistics services provided by agricultural products logistics service providers, including personnel, equipment, knowledge, technology, and other necessary conditions. Process quality is an index to weigh the degree of logistics plan formulation and implementation during the operation of agricultural products logistics. Result quality is to measure the technical result of service provided by agricultural products logistics service providers and the degree of impact on customers.

Logistics cost index is to weigh the cost control of agricultural products logistics operation and management. The cost of agricultural products logistics comprises explicit logistics cost and implicit logistics cost. Explicit logistics

\section{B. Influence Factors of Agricultural Products Logistics Efficiency}

1) Low organization degree of agricultural products logistics: Generally speaking, China has abundant agricultural products resources, but they are scattered, and its operation and management are mainly controlled by individual household, enterprise and peasants' cooperative. Therefore, the agricultural products logistics organization is scattered, and small in scale and large in quantity. Due to the lack of effective logistics resources integration, it is difficult to achieve a systematic and integrated management on logistics, let alone effect of logistics scale, resulting in low efficiency of agricultural products logistics.

2) Low informationization degree of agricultural products logistics: Restricted by space, region, scale, investment and other factors, the current agricultural products logistics, especially in remote areas, is far from being informationalized, which directly leads to the coordination deviation in the overall operation of agricultural products logistics. Moreover, unreasonable distribution of logistics resources and asymmetric logistics information make it difficult for member enterprises of agricultural products logistics supply chain to conduct scientific communication, planning, and coordination. As a result, the whole supply chain of agricultural products logistics industry cannot respond to the market in time, thus losing market competitiveness.

3) Inadequate modern agricultural products logistics infrastructure: Now, agricultural products logistics infrastructure mainly consists of agricultural products logistics center, agricultural products wholesale market, agricultural products trade market, etc. Although it is much better than before, there are still some defects. For example, shortage of modern automatic temperature control cold storage, insufficient application of Internet of things technology in agricultural products logistics infrastructure, and logistics information technology infrastructure in the primary stage seriously restrict the operation efficiency of agricultural products logistics.

4) Shortage of technical means in the supervision of the whole process of agricultural products logistics: Due to the characteristics of agricultural products, together with relatively backward informatization and intelligent construction of the current agricultural products logistics facilities and equipment, and a regulatory mechanism that has not yet been fully established, now the whole process of agricultural products logistics lacks effective supervision, and violations often occur in the logistics process of 
common logistics, make advanced analysis and customized analysis as required by each member enterprise and customer in the supply chain of agricultural products common logistics, and provide in-depth insight for each member enterprise and customer. Besides, it will also integrate and manage data information, provide complete data about the management and control of life cycle, and build intelligent common logistics of agricultural products.

2) Public big data platform for agricultural products common logistics: The platform is not only open to the customer market through the data interface, but also receives big data information through data interface. Big data provides a large amount of logistics service information for each member enterprise and customer of agricultural products common logistics, including various agricultural products logistics providers, various logistics infrastructure information, various logistics equipment information, various transportation and distribution resource information, logistics human resource information, agricultural products logistics scheme design ability and resource information, agricultural products logistics advantages and restrictive policy resource information, agricultural logistics insurance information, agricultural logistics financial information and so on. These information are gathered into virtual logistics resources and capabilities, forming the big data resources of agricultural products common logistics service on the public information platform of agricultural products logistics, providing the search and query for member enterprises and customers of agricultural products logistics.

3) Big data management platform for agricultural products common logistics: Through radio frequency identification device, global positioning system, navigation system, vehicle transportation management system, warehouse management system, distribution management system, car networking, sensor, sensor network, big data management platform for agricultural products common logistics can accurately and quickly handles the customer order in each link of agricultural products logistics supply, and can dispatch, coordinate and direct various types of logistics resources based on the operation of the common logistics system. In addition, it can plan each logistics node, logistics route, and logistics method as a whole, provide integrated logistics solutions, carry out some common logistics services, such as common storage, common transportation, joint distribution, common distribution processing and common reverse logistics, realizing the intelligent identification and management of common logistics big data management platform on logistics resources and logistics requirements.

\section{CONCLUSION}

In general, it is necessary to promote the common logistics operation mode of agricultural products from organizational management, apply cloud computing technology and RFID intelligent logistics management equipment and common logistics tools. Then, it will analyze the data, establish a large database of agricultural products 
technology at the technical level to design and construct the common logistics big data management platform of agricultural products. For one thing, it makes it possible for real-time collection, transmission, analysis, quality safety and accurate traceability of information in all links of agricultural products logistics. For another, big data analysis of agricultural products can provide a strong guarantee for the implementation of the common logistics of agricultural products, effectively improve the efficiency of agricultural products logistics, better meet the goals of agricultural products logistics on improving logistics service quality and reducing logistics costs, thus better meeting the needs of economic development.

\section{REFERENCES}

[1] Ma Lili. Bottleneck and Breakthrough of China's Agricultural Products Logistics in China in the Era of Big Data [J]. Agricultural Economy. 2016. 3. (in Chinese)

[2] $\mathrm{Hu} \mathrm{Yu}$. The Challenges and Countermeasures of Agricultural Products Logistics Under the Background of Big Data [J]. Reformation \& Strategy. 2016. 4. (in Chinese)

[3] Jiang Xuelin, Wang Shaofen, Huang Fuhua. Research on the Strategies of Improving the Logistics Efficiency of Fresh Agricultural Products from the Perspective of Common Logistics [J]. 2016. 5. (in Chinese) 